\title{
17. How innovations catalyse the circular economy: building a map of circular economy innovation types from a multiple-case study ${ }^{1}$ \\ Anil Engez, Valtteri Ranta and Leena Aarikka-Stenroos
}

\section{INTRODUCTION}

In the field of environmental sustainability, the circular economy (CE) has attracted global interest concerning resource efficiency, conservation of natural resources, and increasing carbon neutrality (Ghisellini et al. 2016). The CE has been identified as a concrete means of implementing sustainability into business (Ghisellini et al. 2016) and is strongly driven by innovation, as it requires firms to introduce novel products and processes that adhere to CE principles (Prieto-Sandoval et al. 2018). In the CE, the value of materials and products is maintained to reduce demand for virgin natural resources (Geissdoerfer et al. 2018). Thus, it may require companies to adapt or replace their current business models (Prieto-Sandoval et al. 2018) and innovate in diverse ways (Mariadoss et al. 2011) to generate innovation that catalyses the CE.

Environmentally sustainable innovations have been framed as eco-innovations (De Jesus and Mendonça 2018; Hellström 2007; Prieto-Sandoval et al. 2018; Rennings 2000) and product and CE business model innovations (Bocken et al. 2016; den Hollander et al. 2017; Vasiljevic-Shikaleska et al. 2017). Eco-innovations are socio-technical solutions that preserve resources by allowing for the recovery of resources and mitigate environmental degradation (De Jesus and Mendonça 2018). Thus, they provide a foundation for CE innovations. Studies have highlighted the potential of eco-innovations to contribute to environmental sustainability but have under-explored the related aspects of innovation management. The consequent research gap regards the innovation types that enable the CE and the sustainability issues that those innovations aim to solve. To address this gap, the present chapter examines the diversity of CE innovations through innovation management lenses to illuminate the innovation needs of firms, which range from technology to business development for sustainability and the CE. To this end, it maps CE innovation types and their characteristics to uncover innovation diversity in the $\mathrm{CE}$ in theory and to guide managers and practitioners in their innovation efforts to develop sustainable solutions. The study considers three research questions (RQs):

RQ1: What are the CE innovation types from the technology and innovation management perspective?

RQ2: Which sustainability issues are addressed by the CE innovations?

RQ3: Which benefits do CE innovations pursue?

We apply an analysis framework that differentiates between four organizational innovation types: product, process, service, and business model innovations (Crossan and Apaydin 
2010). We further divide each innovation type into three sub-types based on our analysis. Following this categorization, we provide examples for each sub-type with references to CE innovations developed by various companies. Our study not only introduces a new, nuanced, and explicit categorization of CE innovations with comprehensive sub-types but also explores the pursued sustainability implications and the pursued benefits of the various types. While similar studies have been limited to the descriptive and explorative level and focused on the product design and business model strategies (Bocken et al. 2016; den Hollander et al. 2017; Vasiljevic-Shikaleska et al. 2017), this research extends the CE innovation categorization approach by presenting the process and service innovation categories along with the relational aspect of CE innovations and sustainability issues. Consequently, the study connects the CE with technology and innovation management research streams.

This chapter is structured as follows. After the introduction, the second section discusses the innovation types in the CE to explain the theoretical background of the study. The third section then presents the research design. Subsequently, the fourth section examines product, process, service, and business model innovations and their sub-types through company offerings. The final section concludes the chapter and specifies the theoretical contribution, practical implications, and future research avenues.

\section{INNOVATION IN CE: INNOVATION TYPES}

The $\mathrm{CE}$ is a restorative and generative economic system that aims to maintain the value of products, materials, and resources by reducing, reusing, recycling, and recovering materials in production/distribution and consumption processes (Kirchherr et al. 2017; Ranta et al. 2018). In CE, innovations are developed to slow and close resource loops (Bocken et al. 2016). Slowing resource loops refers to the process of decreasing the rate of material flows from production to recycling. It can be achieved by extending a product's lifespan through the use of durable materials and a design that is repairable, reusable, upgradable, and suitable for disassembly and reassembly (Bocken et al. 2016; Stahel 2016). Meanwhile, closing resource loops refers to a recycling process that utilizes materials from products that are no longer usable. Therefore, it seeks to close the loop between post-use waste and production (Stahel 2016). These two approaches are dominant in CE innovation literature. To expand this view and ground $\mathrm{CE}$ innovations in innovation management literature, we review the innovation types of product, process, service, and business model innovations (Crossan and Apaydin 2010) within their CE context.

\section{Product Innovations}

Product innovation is realized as an assembled product that is sold to a customer once it is manufactured and which evokes perceived newness, novelty, originality, uniqueness, and usefulness of the innovation (Henard and Szymanski 2001). When developing product innovations for the $\mathrm{CE}$, it is important to apply sustainability principles at an early stage in the product design process. These principles include designing for a technological cycle (emphasizing the cycle of the products of service), a biological cycle (using materials that can biodegrade through e.g. composting), disassembly and reassembly, product-life extension, and long-lasting products (Bocken et al. 2016; Vasiljevic-Shikaleska et al. 2017). Another 
approach to classify CE product innovations considers the integrity and recycling aspects in the product design (den Hollander et al. 2017). Designing for integrity focuses on preventing obsolescence at the product/component level, while designing for recycling applies such focus at the material level.

\section{Process Innovations}

Process innovation refers to the implementation of "new production methods, new management approaches, and new technology that can be used to improve production and management processes" (Wang and Ahmed 2004, p. 305), which describes processes that enable internal value creation for a firm (Crossan and Apaydin 2010). A process innovation may lead to the emergence of new products or enhance an existing product's performance, design, and cost attributes or the materials/components of which it is composed (Maine et al. 2012). Therefore, process innovations are not only internal to one firm but can also be commercialized and transferred to other firms.

\section{Service Innovations}

A service is an asset that serves a customer need and provides a benefit to the customer. Thus, it is an inherent value that is transferred from the provider to the recipient (O'Sullivan et al. 2002). Service innovation emphasizes the development of new service offerings and concepts and intertwines tangible (e.g. product forms) and intangible (e.g. processes, knowledge) aspects of an innovation (Kindström and Kowalkowski 2014), in which information technology is influential. As the digital era departs from the goods-dominant logic of value creation, service innovations need to be network-centric, information-centric, and experience-centric to remain competitive in the market (Lusch and Nambisan 2015). This need requires firms to realign their dynamic capabilities of sensing opportunities and threats, seizing opportunities, and reconfiguring their resources (Kindström et al. 2013; Teece 2007). The service-dominant logic dictates that firms must concentrate on actor-to-actor networks, digitize information, and densify and integrate their resources (Lusch and Nambisan 2015). In the CE, services can reduce the overall use of resources by allowing multiple users to share underutilized resources or helping to optimize the use of resources by a single user (Ranta et al. 2020). Furthermore, services contribute to closing loops through recycling (Stahel 2016).

\section{Business Model Innovations}

A firm's business model consists of three main elements: the value proposition to customers, value creation and delivery, and value capture (Teece 2010). Business model innovation entails changes in an organization's business model elements, which concern the target segments, the offering, value chain organizations, revenue capture mechanisms, and the value proposition itself. Business model innovation complements the traditional subjects of process, product, and service innovations by devising a novel way of creating, delivering, and capturing value (Foss and Saebi 2016). In the CE, circular business models aim to generate profits from the flow of materials and products over time (Bocken et al. 2016). 


\section{RESEARCH DESIGN}

Since the current literature on innovations in the field of CE is nascent, we employed an explorative approach to fulfil our objective. Specifically, we conducted a multiple-case study of 27 firms from Finland with 27 innovative offerings that have been introduced to domestic and global markets to catalyse the CE. To sample forerunners and suppliers with innovative offerings, we selected our cases from a compilation by the Finnish Innovation Fund (SITRA), which is a national leader and independent expert organization in promoting awareness of CE and the technology industries of Finland. The offering descriptions include suppliers' explanations of new features of the offering (i.e. innovation reflecting the sustainability transition) and the value that the offering imparts to customers and the provider. Following our strategy for gathering a comprehensive and inclusive data set, the offerings are based on a variety of innovations, including unprecedented usages of recycled materials, new services for lengthening product lifecycles, novel and more sustainable production processes, and new business models for reusing and sharing products. Thus, they cover each of the innovation types identified in the literature.

As our units of analysis, we used the four aforementioned innovation types. The analysis chart lists the following aspects: the main innovation types, three sub-types, innovation examples per sub-type, the company that developed the innovation, the main sustainability issue addressed by the innovation, and the pursued benefit/value. The final framework synthesizes the chart into a conceptual figure that depicts the CE innovations and their sub-types in the form of a tree diagram.

\section{FINDINGS}

Our analysis of 27 innovative offerings by forerunner firms in the Finnish CE ecosystem encompasses the four innovation types and their value in terms of sustainability. The analysis informed a map of the main CE innovation types and their sub-types (see Figure 17.1).

The next sections detail our findings per CE innovation type with examples. Table 17.1 contains an overview of the CE innovation types and their corresponding sub-types, example offerings from companies, explanations of the main sustainability issues that the innovations address, and the pursued benefits. A detailed analysis follows.

\section{Product Innovations}

\section{Recyclable products that are suitable for return to circulation}

As an example of this innovation type, Honkajoki produces fertilizers made from organic waste from local communities and industrial operators. In industrial plants, animal-based waste is converted into raw materials for the energy, cosmetics, fertilizer, and animal feed industries. A second example is the biochar product by Carbons/Carbofex. The pyrolysis process produces biochar along with gas, pyrolysis oil, wood vinegar, and heat. The latter can be distributed in the district heating network. Because of its high water and nutrient absorption capacity, biochar is effective as a biofilter in stormwater management systems and a growing medium in agriculture and for the treatment of seepage water runoff. A third example is Durat's production of recycled interior design materials from plastic waste, which uses recy- 


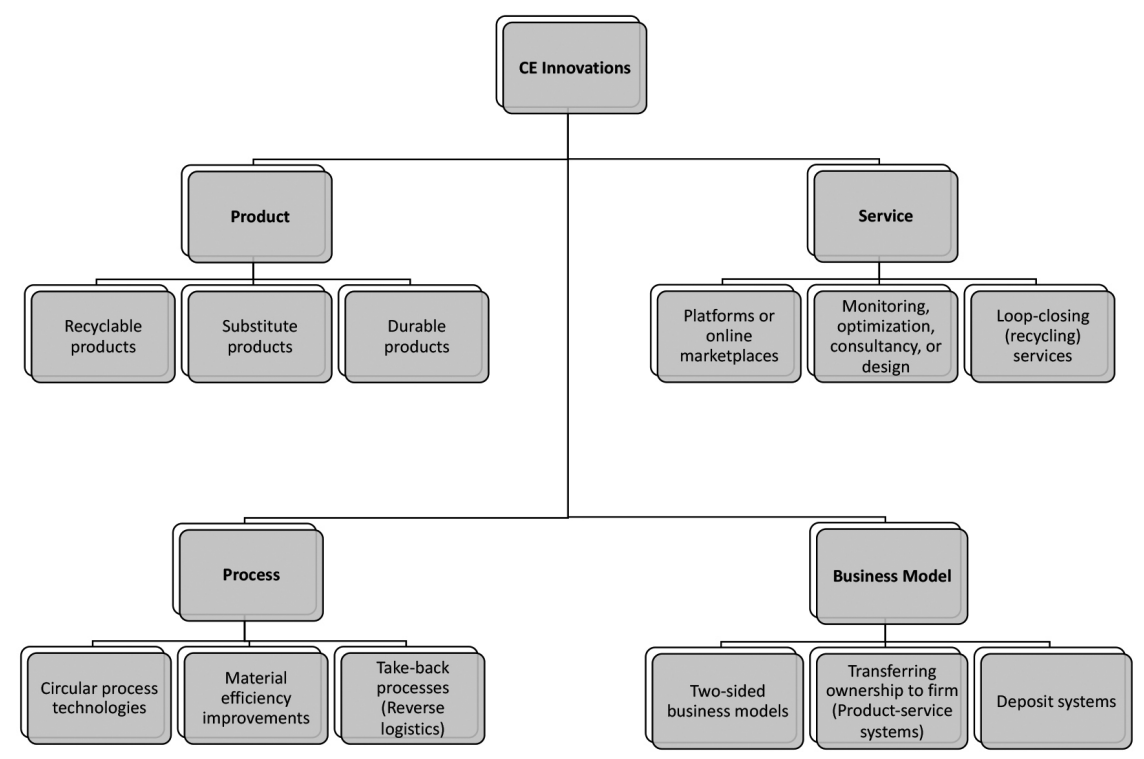

Figure 17.1 The main CE innovation types and their sub-types

cled post-industrial plastics to create interior materials, such as kitchen and bathroom sinks and kitchen worktops. Recycling reduces the demand for virgin raw materials.

\section{Substitute products that are more sustainable than their traditional alternatives}

Substitute products intend to replace current unsustainable products. An example is Gold $\&$ Green's range of plant protein products made from oats and legumes as alternatives to meat-based products. Meat production is inherently unsustainable due to the high greenhouse gas emissions that result from methane production by livestock (Steinfield et al. 2006). Similarly, bio-based renewable materials intend to replace non-renewable materials, such as plastics. One example is Sulapac's development of biodegradable packaging products that use wood- and plant-based binders, such as wood chips and cellulose. The reusability, recyclability, and biodegradability attributes of these renewable materials define them as a sustainable alternative to plastics.

\section{Durable products with a long lifespan}

Durable products have a long utilization period. Durable products include high-quality materials and components that last longer without breaking down or becoming worn out, which extends the product's lifespan. An example of this innovation is a laser coating created by Kokkola LCC that increases the durability of metal parts in the metal, energy, and process industries. Durable products require fewer repairs and component replacements over time, which slows resource loops by eliminating new raw material usage. They also enable users to reduce repair and maintenance costs, although their purchase price might exceed that of regular products. 


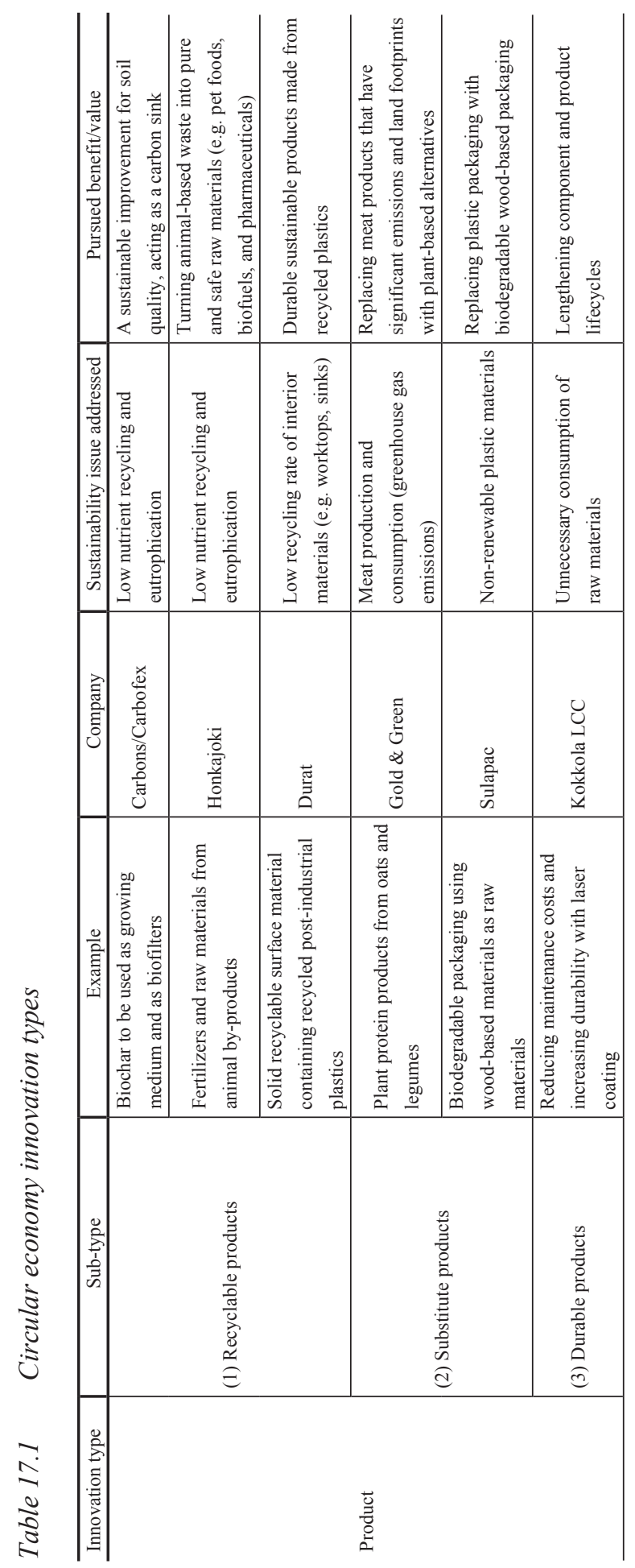




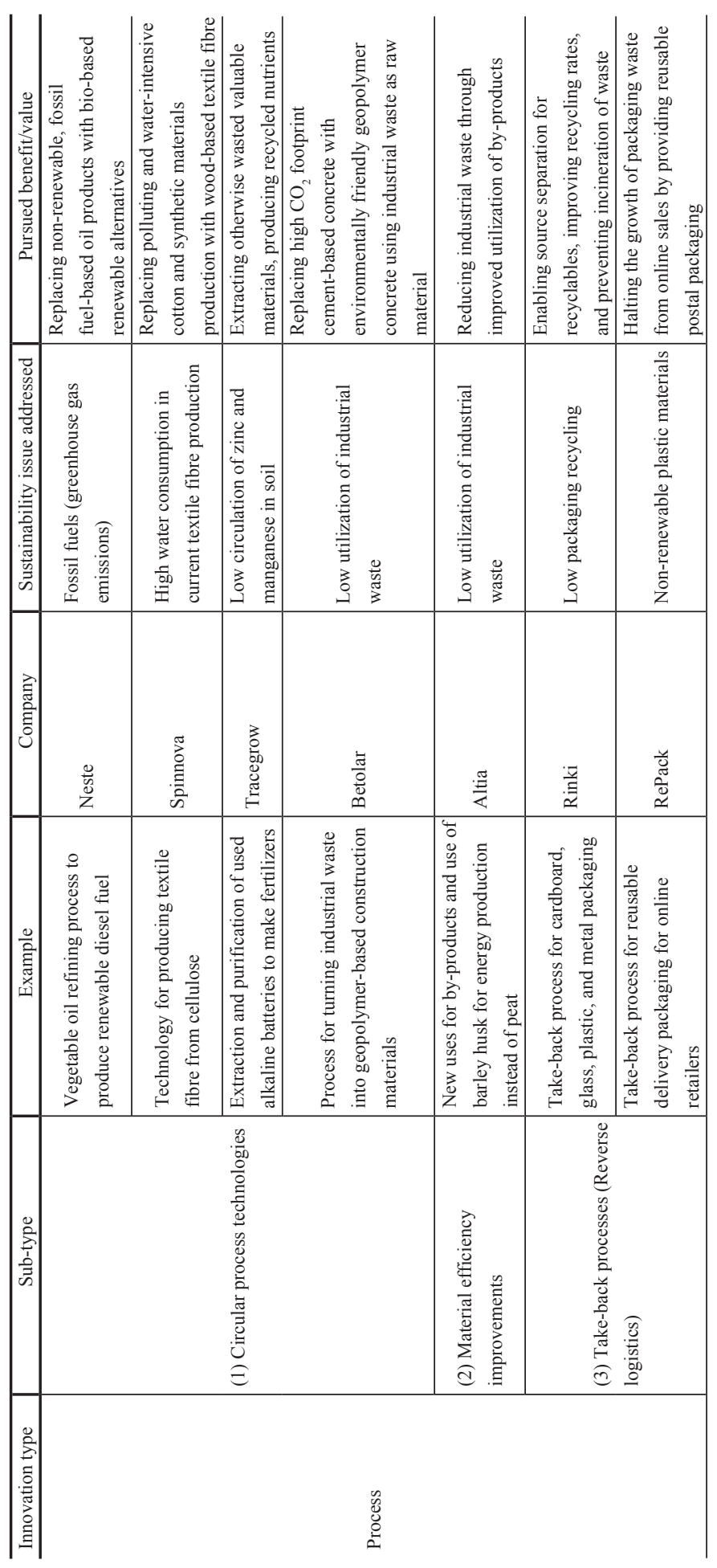




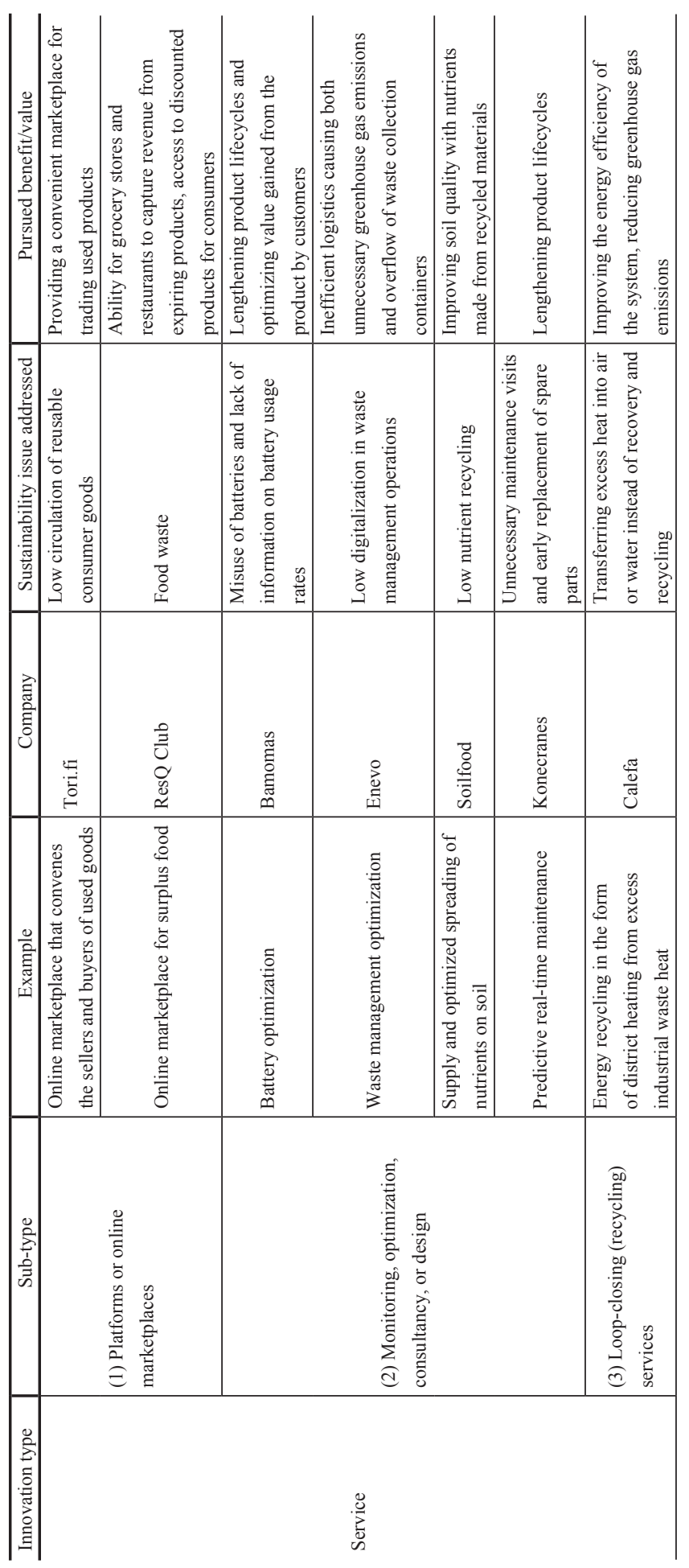




\begin{tabular}{|c|c|c|c|c|c|c|c|}
\hline 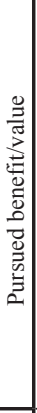 & 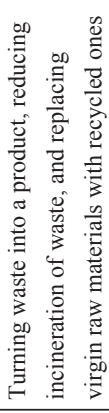 & 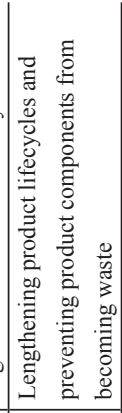 & 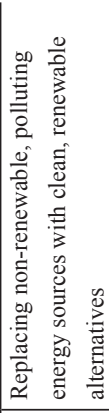 & 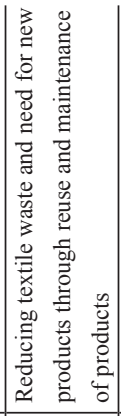 & 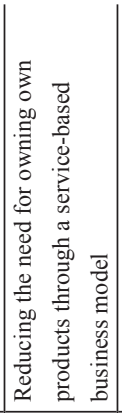 & 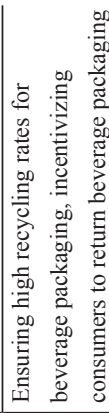 & 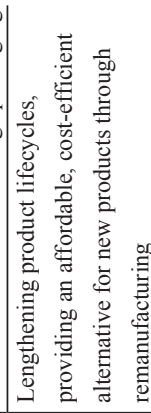 \\
\hline 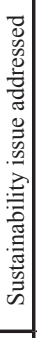 & 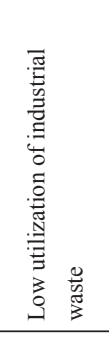 & 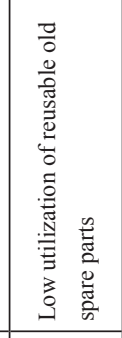 & 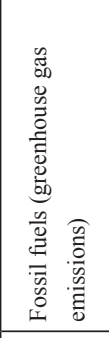 & 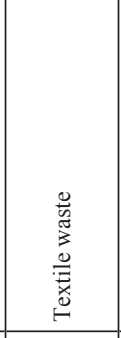 & 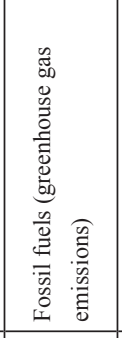 & 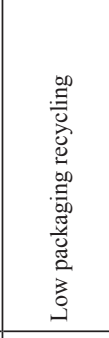 & 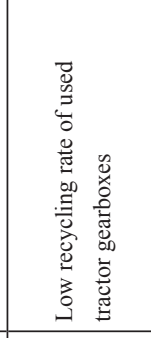 \\
\hline 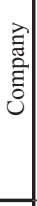 & $\sum_{S}^{5}$ & $\begin{array}{l}\mathscr{0} \\
\tilde{E} \\
\tilde{E}\end{array}$ & $\frac{n}{z}$ & 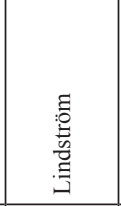 & 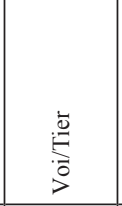 & 㺃 & $\frac{\pi}{\stackrel{\Xi}{\pi}}$ \\
\hline 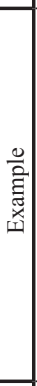 & 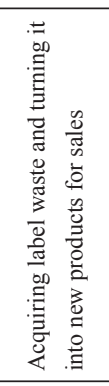 & 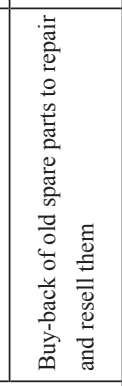 & 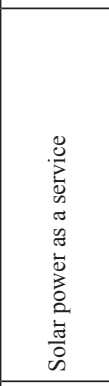 & 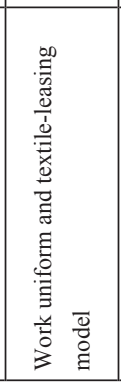 & 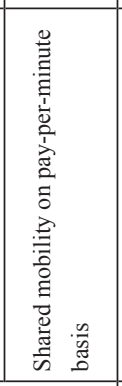 & 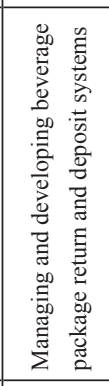 & 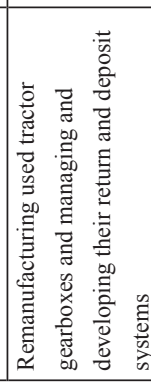 \\
\hline 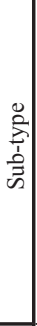 & & 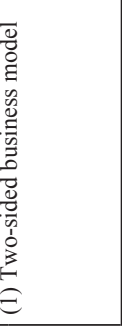 & & 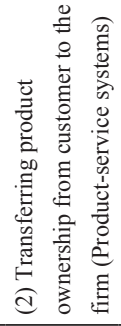 & & & 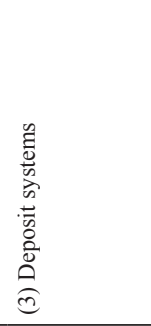 \\
\hline 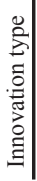 & & & & 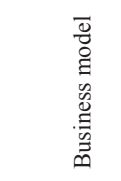 & & & \\
\hline
\end{tabular}




\section{Process Innovations}

\section{Circular process technologies that enable novel and efficient processing of a certain type of waste or used product}

An example in this category is the hydrotreated vegetable oil (HVO) refinery process by which Neste produces diesel fuel. This process employs several forms of waste and residue as raw materials (e.g. used cooking oil, animal fat from food industry waste, and vegetable oil processing waste and residues). Generating diesel from renewable materials results in up to a 90 per cent reduction in greenhouse gas emissions compared to fossil diesel production. Another example is Spinnova's process of producing textile fibre from cellulose. The company partners with a eucalyptus pulp producer, an expert company in cellulose fibre, and several clothing brands. Other examples in this category include Betolar's transformation of industrial waste into geopolymer-based construction materials and Tracegrow's extraction and purification of used alkaline batteries to produce organic fertilizers.

\section{Material efficiency improvements to increase utilization rate}

Material efficiency improvement processes aim to maximize the utilization rate of a material by modifying the material or its use process. Because the material can be used for longer periods, the higher utilization rate reduces carbon dioxide emissions and costs by eliminating the need for new raw material production/usage and providing energy savings. An example in this category is the usage of barley husk as the main fuel for steam energy production in Altia's Koskenkorva distillery. The plant uses barley grain to manufacture the spirit and produces starch and animal feed as sidestreams. In this process, carbon dioxide is captured and employed in greenhouse farming, and ashes are given to farmers to use as fertilizer, which results in a material efficiency of 99 per cent.

\section{Take-back processes for products that are no longer in use (reverse logistics)}

In this category, firms take back usable materials or parts of a product and return them to the market for reuse, optionally after remanufacturing or recycling them. Producers benefit from this process through profits generated from the reuse, remanufacture, or recycling processes of reclaimed products and materials. An example is the eco take-back point network of Rinki, which has over 1,850 take-back points for cardboard, glass, and metal packaging and over 500 take-back points for plastic packaging. The collected packaging waste materials are processed into raw materials for new products. Another example is RePack's reusable delivery packaging for online retailers. The take-back process starts when end users return empty packages by post for free. They are rewarded for returning the packages, which enables a high return rate. Apart from packaging, batteries, cars, and electronics are other consumer products that are widely considered suitable for take-back processes and further refurbishing or recycling.

\section{Service Innovations}

\section{Platforms/online marketplaces on which people can connect and share or sell used products}

An example of this innovation is Tori's online platform, which facilitates consumer-to-consumer (C2C) sales and thus slows resource loops by encouraging the reuse of goods. As another example, ResQ Club targets the issue of food waste by offering a location-based online 
platform on which restaurants and supermarkets can sell their surplus or nearly expired food products at a discount at the end of the day. Once the food products are posted on the platform, end-users can pay the reduced price online and collect the food from the restaurant or supermarket. This service allows restaurants and supermarkets to generate additional revenue from surplus food that would otherwise be wasted. Additionally, it enables customers to save time on cooking and enjoy restaurant-quality food.

\section{Monitoring, optimization, consultancy, or design services}

As an example in this category, the company Soilfood, which specializes in nutrient recycling, offers soil improvement services to its clients. The company supplies and spreads recycled nutrients on soil according to the soil properties. By using recycled nutrients as organic fertilizers, farmers can improve crop yields while minimizing fertilizer costs. Another example in this category is Bamomas' extension of the lifespan of industrial batteries through optimization. This service uses sensors for measuring the voltage, current, temperature, and water refill levels of the batteries to pursue more efficient use of batteries through maintenance and the detection of end-of-life batteries for replacement. A third example is Enevo's collection of data from waste management operations for optimization analysis. The company installs sensors inside waste containers to monitor the fullness of the container. This information allows waste collection once a container is completely full, which lowers logistics costs. The sensors are key to monitoring and optimization services, as both cases employ them in providing their services. A fourth example in this category is the predictive real-time maintenance service of Konecranes, which eliminates unnecessary maintenance visits and early replacement of spare parts. The service benefits both suppliers and customers, as both parties can save on time and costs. The services in this category can be diversified by using different types of sensor, such as vision and imaging, temperature, proximity, position, pressure, or humidity sensors.

\section{Loop-closing (recycling) services}

As an example in this category, Calefa recycles energy from excess industrial waste heat to convert into district heating. Recycling the waste heat reduces costs and carbon dioxide emissions, as the captured heat can be sold or reused in buildings, and it minimizes the additional heat generation requirement. The company closes the loop by recovering and recycling the excess heat instead of transferring it into the air or water.

\section{Business Model Innovations}

\section{Diversification of the business model through a two-sided design}

In this category, a single firm provides waste management services to obtain the required raw materials and then produces new products from those materials. For example, the forest industry company UPM offers recycling services for self-adhesive label by-products and then transforms them into magazine paper, paper liner, composite material, or energy. The company maintains a two-sided business model that establishes a waste management service for customers of its label business alongside an entirely new business of producing and selling products that are made from the label waste. As another example in this category, the business model of Ponsse, which specializes in forestry vehicles and machinery, entails buying back its old spare parts to later repair and resell them. This approach increases the utilization rate of reusable old spare parts. 


\section{Transferring product ownership from customer to firm (product-service systems)}

These innovations replace the one-time product purchase fee for customers with continuous service fees throughout the use of the product. Lindström has adopted this business model in leasing work uniforms and equipment to its clients for a certain period. With this service, companies can avoid spending a large lump sum on work uniforms, and they can focus on their core business activities while the provider company assumes responsibility for clothing maintenance and ensures that the equipment is in good condition and has a long lifespan. Another example is the design, implementation, and maintenance of photovoltaic systems (e.g. solar panels) for clients by NAPS. The company generates revenue by periodically billing its clients, who only pay for the photovoltaic power produced on their roofs. A final example in this category is the rental of electric scooters by Voi/Tier via a mobile application, where users pay on a per-minute basis.

\section{Deposit systems where customers reclaim deposit amount upon returning used products}

An example in this category is a bottle return system by Palpa. The broad range of the beverage bottle recycling network in Finland facilitates a beverage container recycling rate of over 90 per cent. When a customer buys a beverage from a supermarket, its price includes a deposit for the bottle, which can be reclaimed by returning the empty bottle to an automated reverse vending machine. The machine transfers the bottle to the respective container for its material (e.g. glass, plastic, or can), which it identifies by scanning the barcode of the bottle. The machine automatically compresses the collected plastic bottles and cans to accommodate more returns and increase the cost efficiency of transportation. Once the materials are transported to the recycling centre, they are further processed into raw materials for new beverage bottles. The recycling of cans is highly sustainable; because of the lightness and durability of aluminium, it consumes only 5 per cent of the energy of the first manufacturing process. Meanwhile, coloured plastic bottle flakes can be repurposed as raw material for the textile industry. The whole process is carried out by the non-profit company Palpa. Cooperation among the manufacturers and importers of beverages, consumers, stores and supermarkets, logistics companies, and operators is vital to realize an efficient recycling process.

Another example is the innovation of Valtra, which specializes in tractor and agricultural machinery manufacturing, in its deposit scheme for used tractor gearboxes. In this model, the company remanufactures used tractor gearboxes, and it manages and develops their return and deposit systems. Remanufactured gearboxes are sold at a price that is $30-40$ per cent lower than that of new products. In addition to the purchase price of the remanufactured gearbox, the customer pays for an additional deposit that amounts to approximately 50 per cent of the gearbox price. If the purchased gearbox breaks down after the one-year warranty period, the customer can return it to the company and reclaim the deposit. The company will then take back the broken gearbox, fix it, and remanufacture it for the next customer. Remanufacturing requires nearly 85 per cent less energy than manufacturing a brand new gearbox.

\section{DISCUSSION AND CONCLUSIONS}

Studies on sustainability and CE transition have strongly emphasized the role of 'eco-innovations' (De Jesus and Mendonça 2018; Hellström 2007; Rennings 2000). This 
chapter has employed the term 'CE innovations' to highlight the recirculation of resources in reuse, recycling, and renewal processes to slow and close resource loops (Bocken et al. 2016). The term also stresses the significance of the circularity aspect of the innovations for sustainability. We have divided CE innovations into four types and three sub-types for each for a total of $12 \mathrm{CE}$ innovation sub-types. Our categorization is based on Crossan and Apaydin's (2010) framework of organizational innovation as an outcome and thus connected the CE and technology and innovation management stream, which supports a clearer understanding of the $\mathrm{CE}$ for organizations that are at the forefront of advancing the CE (Vasiljevic-Shikaleska et al. 2017). Our analysis reveals four innovation types in the CE (product, process, service, and business model) and provides insight into their benefits and sustainability impacts. The CE innovation types are here considered as categories in a typology (not a taxonomy), in which each type is kind of archetype. Therefore, the types can overlap and interact (e.g. technological process innovation can lead to a business model innovation), and an empirical case can hold characteristics of several CE innovation types.

\section{Theoretical Contributions}

The examination of the main CE innovation types in this study contributes to innovation literature in the areas of eco-innovation and sustainable innovation (De Jesus and Mendonça 2018; Hellström 2007; Rennings 2000). To build on the typology of innovation forms by Crossan and Apaydin (2010), the study has cited examples of CE innovations and further categorized them into their corresponding innovation type. Therefore, the study has devised a new typology for CE innovations that can increase raw material availability, energy savings, and product/material utilization rates over the lifecycle as well as reduce carbon emissions. This study has extended beyond the descriptive and explorative level of previous literature (Bocken et al. 2016; den Hollander et al. 2017; Vasiljevic-Shikaleska et al. 2017), to establish a CE innovation categorization that considers the process and service innovation types alongside the relational aspects of the CE innovations and sustainability issues. Thus, it offers a new, nuanced, and explicit categorization of CE innovations and comprehensive sub-types while addressing ongoing global sustainability issues that can be mitigated by innovating within those categories.

\section{Practical Implications}

The identified CE innovation types and sub-types can guide managers in (re-)designing their customer value propositions and approaches to creating, delivering, and capturing value in line with sustainable development goals. Sustainable design is essential to improve resource efficiency and reduce the negative environmental impacts of products and services. Companies must transform their linear business models into circular ones to meet the urgent demand for sustainable innovations that can combat the acceleration of global warming. The categorization in this study can act as a guide for emerging innovations to be designed taking into account their environmental impact.

The refined categorization of innovation types reveals innovations that enable the introduction of the CE into a firm's operations. Thus, it provides managers with a clear set of options for use in planning. Managers can also apply the categorization to consider the interplay of different types of innovation; for example, business managers who are designing a business 
model for a technological innovation that supports efficient reuse of products should be interested in the process and business model innovations that facilitate profitable implementation of the technological innovation. Meanwhile, technology managers should consider the technological CE process capabilities under development within a firm in light of other potentially necessary types of innovation. Our CE innovation categorization clarifies the CE and can inform idea generation at the beginning of the innovation process.

\section{Future Research Avenues}

This study has explored innovation examples from numerous companies. Future research could examine the dynamics of the relationship between firms and stakeholders in successful introductions of CE innovations. Such findings could deliver crucial guidance for firms in collaborating with stakeholders and for stakeholders in supporting the introduction of the CE in firms.

\section{ACKNOWLEDGEMENTS}

This work is supported by the Academy of Finland's 'Circular Economy Catalysts: From Innovation to Business Ecosystems (CICAT2025)' research funding (grant ID 320194), the Academy of Finland's 'Profi4 - Urban Platform for the Circular Economy (UPCE)' research funding (grant ID 318940), and the research grant that was awarded to Anil Engez by the Jenny and Antti Wihuri Foundation.

\section{NOTE}

1. This is an open access work distributed under the Creative Commons Attribution-NonCommercialNoDerivatives 4.0 Unported (https://creativecommons.org/licenses/by-nc-nd/4.0/). Users can redistribute the work for non-commercial purposes, as long as it is passed along unchanged and in whole, as detailed in the License. Edward Elgar Publishing Ltd must be clearly credited as the rights holder for publication of the original work. Any translation or adaptation of the original content requires the written authorization of Edward Elgar Publishing Ltd.

\section{REFERENCES}

Bocken, N. M. P., de Pauw, I., Bakker, C., \& van der Grinten, B. (2016). Product design and business model strategies for a circular economy. Journal of Industrial and Production Engineering, 33(5), 308-320.

Crossan, M. M., \& Apaydin, M. (2010). A multi-dimensional framework of organizational innovation: A systematic review of the literature. Journal of Management Studies, 47(6), 1154-1191.

De Jesus, A., \& Mendonça, S. (2018). Lost in transition? Drivers and barriers in the eco-innovation road to the circular economy. Ecological Economics, 145, 75-89.

den Hollander, M. C., Bakker, C. A., \& Hultink, E. J. (2017). Product design in a circular economy: Development of a typology of key concepts and terms. Journal of Industrial Ecology, 21(3), 517-525.

Foss, N. J., \& Saebi, T. (2016). Fifteen years of research on business model innovation: How far have we come, and where should we go? Journal of Management, 43(1), 200-227. 
Geissdoerfer, M., Morioka, S. N., de Carvalho, M. M., \& Evans, S. (2018). Business models and supply chains for the circular economy. Journal of Cleaner Production, 190, 712-721.

Ghisellini, P., Cialani, C., \& Ulgiati, S. (2016). A review on circular economy: The expected transition to a balanced interplay of environmental and economic systems. Journal of Cleaner Production, 114, $11-32$.

Hellström, T. (2007). Dimensions of environmentally sustainable innovation: The structure of eco-innovation concepts. Sustainable Development, 15(3), 148-159.

Henard, D. H., \& Szymanski, D. M. (2001). Why some new products are more successful than others. Journal of Marketing Research, 38(3), 362-375.

Kindström, D., \& Kowalkowski, C. (2014). Service innovation in product-centric firms: A multidimensional business model perspective. Journal of Business and Industrial Marketing, 29(2), 96-111.

Kindström, D., Kowalkowski, C., \& Sandberg, E. (2013). Enabling service innovation: A dynamic capabilities approach. Journal of Business Research, 66(8), 1063-1073.

Kirchherr, J., Reike, D., \& Hekkert, M. (2017). Conceptualizing the circular economy: An analysis of 114 definitions. Resources, Conservation and Recycling, 127, 221-232.

Lusch, R. F., \& Nambisan, S. (2015). Service innovation: A service-dominant logic perspective. MIS Quarterly: Management Information Systems, 39(1), 155-175.

Maine, E., Lubik, S., \& Garnsey, E. (2012). Process-based vs. product-based innovation: Value creation by nanotech ventures. Technovation, 32(3-4), 179-192.

Mariadoss, B. J., Tansuhaj, P. S., \& Mouri, N. (2011). Marketing capabilities and innovation-based strategies for environmental sustainability: An exploratory investigation of B2B firms. Industrial Marketing Management, 40(8), 1305-1318.

O'Sullivan, J., Edmond, D., ter Hofstede, A., Benatallah, B., \& Casati, F. (2002). What's in a service? Distributed and Parallel Databases, 12(2), 117-133.

Prieto-Sandoval, V., Jaca, C., \& Ormazabal, M. (2018). Towards a consensus on the circular economy. Journal of Cleaner Production, 179, 605-615.

Ranta, V., Aarikka-Stenroos, L., Ritala, P., \& Mäkinen, S. J. (2018). Exploring institutional drivers and barriers of the circular economy: A cross-regional comparison of China, the US, and Europe. Resources, Conservation and Recycling, 135, 70-82.

Ranta, V., Keränen, J., \& Aarikka-Stenroos, L. (2020). How B2B suppliers articulate customer value propositions in the circular economy: Four innovation-driven value creation logics. Industrial Marketing Management, 87, 291-305.

Rennings, K. (2000). Redefining innovation: Eco-innovation research and the contribution from ecological economics. Ecological Economics, 32(2), 319-332.

Stahel, W. R. (2016). The circular economy. Nature, 531(7595), 435-438.

Steinfeld, H., Gerber, P., Wassenaar, T., Castel, V., Rosales, M., \& de Haan, C. (2006). Livestock's Long Shadow, Environmental Issues and Options. Livestock, Environment, and Development Initiative. Rome: United Nations Food and Agriculture Organization.

Teece, D. J. (2007). Explicating dynamic capabilities: The nature and microfoundations of (sustainable) enterprise performance. Strategic Management Journal, 28(13), 1319-1350.

Teece, D. J. (2010). Business models, business strategy and innovation. Long Range Planning, 43(2-3), $172-194$.

Vasiljevic-Shikaleska, A., Gjozinska, B., \& Stojanovikj, M. (2017). The circular economy: A pathway to sustainable future. Journal of Sustainable Development, 7(17), 13-30.

Wang, C. L., \& Ahmed, P. K. (2004). The development and validation of the organisational innovativeness construct using confirmatory factor analysis. European Journal of Innovation Management, 7(4), 303-313. 